SB 471

. F64

Copy 1 



\title{
SB 471
}

.F64

Copy 1

$$
\text { S U G G E S T I O N S }
$$

$$
\text { O N }
$$

\section{LANDSCAPE GARDENING;}

\author{
By CHARLES FOLLEN,
}

\section{THOROUGH DRAINAGE;}

By J. HERBERT SHEDD,

CIVIL BNGIN RBR.

BOSTON :

PHILLIPS, SAMPSON AND CO.,

13 WINTER STREET.

1859 . 


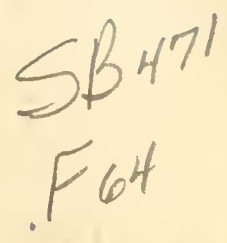

$$
\text { PRESS OF TII }
$$

FRANKIIN PRINTING IIOUSI Corner of Franklin and Hawley Streets, BOSTOX. 


\section{LANDSCAPE GARDENING.}

LaNDSCAPE GaRDENing is a subject in which we are all interested. It is not an abstruse art, shut up between the covers of expensive books. 'It is not dependent on the caprice of individuals, nor on the fashion of the day. Its laws, like other good laws, are consistent with that every-day mathematics common sense. It does not follow, however, that these laws are understood by every man of general sound judgment. In fact, there is, perhaps, no subject on which sensible men act so irrationally, as the treatment of their grounds. It is very easy to say that the cause is ignorance. This is, in a sense, the cause of all our imperfections, and mankind advances mainly by augmenting its stock of knowledge. But the kind of ignorance in this case, is not unacquaintance with authors and systems, but misapprehension as to the objects to be pursued. Some of these objects we propose to point out, and we must first notice some of the prevailing misapprehensions.

We will take first the mistake as to the point of view. Probably most people think that they arrange 
their houses and grounds for their own satisfaction, and it may seem paradoxical to assert that they do no such thing. This is, however, apparently the fact. Sometimes a man lays out his grounds without thinking at all of where he shall put his house. Usually, however, he goes so far right as to fix upon a building place. Now this place he selects mainly with reference to the public road; and he then proceeds to lay out his grounds also with reference to the said road. In short, the whole place is made not to be looked from, but to be looked at. It is astonishing what incohveniences men, not otherwise remarkable for their self-denial, will submit to, in order to present what they consider a good appearance from the street. Often the best aspect is occupied by the kitchen-yard, the stable and out-houses, while the family, from a forlorn, sunless drawing-room, perched in the air, in order that the house may look imposing to passers by, peer through their scattered trees over the dusty road at their neighbors' houses, built like their own, in strict observance of this hideous architectural etiquette. Now if such a man would only stop and think of how very, very little importance it is to the rest of the world where or how he builds his house and arranges his grounds, and, on the other hand, how all important it is to himself, he might avoid that fruitful source of irretrievable mischief - the false point of view.

We may next consider the erroneous idea of combating nature. A writer in the Atlantic Monthly 
has admirably described the prevailing vice of our domestic architecture. "The owner has built himself out of his house, and his house out of the landscape." He not only builds in defiance of the nature of the ground, but he conceives a prejudice against whatever the place naturally affords, and prefers such features as are difficult and costly. He will prefer gravel to grass, and will ostentatiously parade an enormous driveway on the lawn side of his house, thus sacrificing beauty and privacy to a feeling which he would himself, probably, find it difficult to explain. He will prefer a stiff hedge to an informal shrubbery. $\mathrm{He}$ not only choses plants whose culture involves expense and difficulty, but he declares indiscriminate war upon all the indigenous vegetation. Here again the motive for the wrong steps seems altogether inadequate, and they would, probably, in many cases be avoided, if the owner would stop and think, not of what the prevailing fashion demands, but of what will give him real satisfaction.

Lastly, we must notice the delusive idea of obtaining immediate effects. No one, perhaps, deliberately thinks that his landscape is to be realized at once. Yet many act wholly without reference to the future, haste blinding their eyes. There are three ways in which the mischief appears. First, men are in such a hurry to plant, that the question whether the soil is fit for plantations is quite disregarded. Hence arise the starved and sickly specimens everywhere visible. Second, of all the characteristics of a tree, 
that which would seem least liable to be overlooked, is its tendency to grow. Yet trees are constantly so placed that they must in time interfere with each other and with other objects, so that eventually, just as we become attached to them, we are forced to mutilate or destroy them. Lastly, it is a general rule that almost everything done in haste is badly done. The operations of landscape gardening are sometimes spoken of as expensive, yet men do not hesitate to prosecute them with such precipitation, that they are fortunate if they have to do the work no more than twice.

Thus far we have spoken only of what to avoid; let us now look at the positive side of the subject, and consider what to pursue; and, first of all, how to begin. We must, at the outset, make ourselves well acquainted with our land. Look first at the direction of its inclinations. Southern slopes are among the prime resources of an estate; and, in our country, the West is, for several reasons, rather preferable to the East. Next consider the views. These are to be estimated not only for their intrinsic beauty, but with reference to direction, to accessibility, to permanence, etc., etc. Small peaked hills, whence one gets an extended prospect, are common enough, and of comparatively little value; while a sheltered South-western slope, commanding a valley or water view, the objects of interest lying mainly on our own ground, so that the prospect cannot be cut off and may be indefinitely improved, - this is invalu- 
able. We must also know our present resources in trees and shrubs, though the vegetation, since almost entirely in our own control, is of less moment than the shape of the land. Lastly, the soil itself should be. examined, and chiefly because this also is in our power, at least to modify considerably.

Out of this general investigation must grow our plan. The point on which all turns is the position of the house. When we remember that nine-tenths of the pleasure which we shall have in our grounds will be got by looking from windows, piazzas, and terraces, we shall take care that no minor considerations deter us from selecting that spot whence most may be quietly enjoyed; and, the position of the house being settled, let us resolutely subordinate other parts to this all important feature. It is evident now that the more definite plan we can have the better, and that, if we could be sure just where every tree ought to grow, it would be an advantage. But it is equally certain that we cannot have at once this desirable exactness. One sometimes sees plans, made after a cursory view of the ground, finished with very suspicious accuracy; for every one who thinks of the matter, must know that designs, to be of value, must be founded on considerable acquaintance with the place; and, even then, it is nearly impossible to direct rightly on paper the position of every separate tree. There are many of these positions which ought to be determined by looking often from the given point of view, some object, such as a pole or a circle 
of stakes, being set up to represent the desired piece of foliage, in the way so well described in the supplement to the new edition of Downing's work, by which Mr. Sargent has enhanced the value of a book already dear to all students of this subject. Nevertheless, when designs on paper truly represent well understood and deliberately planned improvements, they are of great service, and such ought by all means to be made and carefully followed.

Meanwhile, though we move with deliberation, we need not lose a moment. Simultaneously with our planning we may begin our planting. If any part of the land is fit for a nursery, we may stock it at once. If not, we must prepare a piece as quickly as possible, and then fill it with small trees and shrubs - the general rule being that the nursery be rather too large, rather too well prepared, and the number of plants decidedly more than enough. This, like every other right move in gardening, is a measure of economy.

While the nursery is going on, and as soon as the outline of our plan is settled, we must begin to improve the soil. In every sense thorough draining lies at the bottom of all. It is now proved that all cultivable land is the better for it; and the only question is, whether in certain soil, for certain purposes, the benefit is worth the cost. Without attempting here to decide these cases, it is enough for our purpose to know that for nurseries, gardens, plantations and lawns, drains are almost always indispensable. 
Their chief benefits are warming, ventilating, and deepening the soil; and our next care should be to extend these effects by ploughing, subsoiling, and judicious manuring. How much of these is worth while, must be determined by the circumstances of each case, but we may be sure that, to some extent, they are absolutely necessary.

At length, when the soil is prepared, we may move our trees, at the most favorable time, and from our own nursery, to make our plantations. Our previous measures having given us complete control over all the circumstances, we proceed sure, not only of success, but of rapid realization. It is astonishing to those not familiar with such work, to see in how few years beautiful landscapes can be obtained, provided we have the courage and patience to move with deliberate but constant energy.

Let us now consider some of the effects which it is desirable to produce. The two most important ideas to keep in mind are simplicity and concentration. This need not interfere with that intricacy so effective in large and highly finished grounds; but the refinements must come gradually, - the broad principles first. We will suppose that, in building our house, we have avoided some of the common errors, and that we have placed the room where we are to live, the windows where we really mean to sit, on the side where we get our most desirable view. If an ornamental terrace here connects us with our grounds, so much the better; but we need not be dependent 
on the existence of this feature. Better have no vestige of it than the odious expanse of road which is often made to take its place. We may consider the view from our principal window as divided into foreground and background, of which we can control the first, and, by means of it, modify the second. The foreground must be our lawn. Now, just as a sheet of water depends for beauty on the broken and varied lines of its shore, so does the lawn depend on the outline of its enclosing plantations. It is most important to keep this distinctly in mind. The consequence of neglecting it is that common spotty effect where lawn and plantations get thoroughly mixed together, to the total sacrifice of the landscape. To make this outline picturesque and beautiful our materials are the various forms and colors of our trees. We are not, however left to the exercise of our unlimited fancy. $\Lambda$ moment's thought will show us that the landscape will, like everything else, derive beanty from its limitations. Looking at the unobstructed view, we see at once that some portions of it are much less attractive than others - probably that some are highly objectionable. These our plantations must conceal; and we shall find that, as part of the prospect is shut out, the remainder will be enhanced. In the composition of plantations, though it is clear that true variety is highly desirable, yet it is also certain that the nervous attempts to avoid monotony are a common cause of failure. On the other hand, few effects are more satisfactory, more unwearying 
than a continuous mass of evergreen deeply indented by bright green lawn, and forming a background for fine specimens of oak, maple, and tulip-trees, dressed in their autumnal hues. Yet how few elements are needed to produce this magnificent chord of color! For most eases, the safe and general rule is to avoid too many kinds of large trees, to keep similar foliage together in grand, quiet masses, to reserve strong effects of contrast for the outskirts of plantations, and to admit more and more variety and mixture of species as we use smaller trees and shrubs.

In conclusion, we would offer some suggestions as to the proper office of a landscape gardener. Passing over the elumsy name, which it is now difficult to change and mend, let us consider how the person it means to describe can make himself useful. First, it is elear that he should act as a reformer of the prevailing errors, some of which we noticed above. This office, however, does not exclusively belong to him. Any man of taste, leisure, and observation, is perfectly capable of exposing such blunders. Next, in preparing the soil and forming the nursery, the landscape gardener can, as counsellor, be of great use. It is by no means desirable, however, that he should take the place of the surveyor, drainer, and agriculturist. - If he does so, the result often is inferior work at greater expense, while his attention is diverted from his proper business. This is to study the grounds, and, from this study, to design and to carry out well-considered plans. It is evident, for reasons 
arising from the nature of the case, as we have viewed it, that landscape-gardening is closely connected with architecture. The most unpleasant feature of our buildings is their air of defiance of the nature about them; and nothing can make a country house satisfactory unless it be harmoniously connected with the landscape of which it is the governing feature.

110 Tremont Street, April 11, 1859. 


\section{THOROUGH DRAINAGE.}

IT is now generally admitted that draining holds the first place among mechanical methods for effecting those changes upon the soil by which it is made more productive. No soils can be injured by its judicious application, but all may be benefited to a certain extent. It is useful even in sandy soils, and where the subsoil is light and porous; while in clay lands, and in all cases where stagnant water rests near the surface, it is very important if not indispensable. It is a necessary preparation for other agricultural operations, and, when once thoroughly done, it constitutes a most important, permanent, and yearly increasing improvement, which can be fully produced by no other available means.

A few of the many advantages that result from this process, and which experience has fully proved, are as follows:

The drains not only take off all surplus water at once, - which is an immediate and remunerative benefit, - but they have also begun a process of change and amelioration of the soil, which is gradually deepened, until nearly on a level with the drains. 
The stagnant water which had filled the pores of the soil, (allowing, and aiding in some cases, deposits of peroxide of iron, and in others, deposits of carbonate of iron or of lime, any of which will cement the earthy or stony particles together, forming hard pan,) is removed, and its place is at once supplied by fresh air from the surface, which air is in its turn driven down into the drains by the falling of rain; and this process is constantly repeated. The subsoil is thus made more porous and friable while being mixed with the surface soil, and the deposits which cemented the particles of soil can no longer be made.

Experience has shown that these renewed accessions of fresh air are very valuable in promoting the healthy growth and the quality of all cultivated crops.

It will be noticed that for more readily admitting fresh air, draining is necessary, even in the most porous subsoil. Every new working of the ground increases the efficiency of the drains, and extends that action which gradually but surely improves the depth and character of the soil.

The water of rains running over the surface injuriously washes away the soil. This evil is averted by drains, which allow the surplus water to pass readily through the soil; while in filtering through, it imparts to the soil those substances useful to vegetation which rain water always contains, in more or less abundance. When the water is thus readily carried away, the soil becomes drier, sweeter, and more friable; the hard lumps of clay lands crumble away 
and disappear, the soil working easier and with much more economy.

There is always moisture enough held in the soil by capillary attraction, for all the purposes of vegetation, and which cannot be carried off by any number of drains.

We have found by experiment that an ordinary soil will hold in suspension nearly half its bulk of water; which, in a soil three feet deep, would be equal to nearly six months' rain-fall. Water thus held in suspension does not close the pores of the soil, but still allows free passage of air, since the solid particles, in a friable soil, occupy much less space than the pores between them.

Where the surface soil is porous and gives a ready passage to the water, while the subsoil is compact and impervious, then the roots of plants are compelled to seek their nourishment in the surface soil only.

Air and warmth, as well as moisture, are indispensable to growth, and where stagnant water stops out the air and keeps the soil cold, there can be no vegetation. It is only on the lowering of the water table or surface of stagnant water to a depth of three or four feet from the surface, that roots are free to extend as deep as they may. Roots of wheat and of clover have been traced to the depth of four feet or more, on drained land; and in the streets of cities, roots of shade trees sometimes extend to a depth of eight feet, following the line of sewers. The action of the drains is immediately to withdraw the noxious water; and 
the subsoil, which gradually acquires properties similar to the upper soil, becomes dry and porous to a greater depth. Deeper ploughing, subsoiling, and trenching are now practicable; the plants have a larger space through which to send their fibres in search of food; the elements of a fertile soil are brought into action; and the water in passing through the soil is made of great benefit, instead of doing such injury by remaining stagnant. The result is, that after draining, the increase of produce is often enough to pay the cost of this operation in two or three years. It is obvious from these facts, that the deeper the drains, provided the water has a ready escape, the greater the depth of soil which is made available for vegetable nutrition. Experience has shown that water does find a ready escape into drains four feet deep, and that these are generally more beneficial than those laid nearer the surface. Both the depth and the distance apart must, however, be to a certain extent regulated by the circumstances of the case.

There are no strong and good soils in which the water table naturally stands at a sufficient depth from the surface. All such soils will be materially benefitted by thorough draining, whatever their position may be, or the inclination of their surface.

Thorough drainage prevents freezing out, or that process of crystallization of the surface which draws young plants from their beds.

A given quantity of manure will last longer and do more service on drained than on undrained land. 
The farmer who adopts this system is less at the mercy of the fickle elements; for an efficient drainage carries off the water so rapidly that his ground is fit to work as soon as the rain has ceased, and he is not obliged to "wait for the land to dry." He has also a longer season for his work, since the ground is ready for crops earlier in the spring, and can be worked later in the fall.

Another great advantage which follows the practice of thorough draining, is the effect it has in raising the temperature of the soil.

Heat will not pass downward in water, and, before a soil can be warmed, the water must be removed. Again, water escapes from retentive, undrained soils by evaporation only, - a process which uses up a great amount of heat; one pound of water in passing into a state of vapor absorbing and carrying away $972^{\circ}$ of heat, which is rendered latent or insensible to the thermometer. This amount of heat might have raised the temperature of the soil, and materially assisted the process of growth had it not been lost by evaporation. Prof. Henry gives, in the last Patent Office Report, a table by II. Schubler showing the maximum temperature of various earths exposed to the sun, while the surrounding air was at about $78^{\circ}$. One column exhibits the temperature of moist earth, and the other that of dry earth. He remarks, that "the differences of temperature exhibited by the two columns are due to the heat expended in the evaporation of a portion of the water in the moist earth." 
In six cases of different kinds of soils, the least difference between the two columns is $13^{\circ}$ (in calcarious sand); and the greatest difference is $13.95^{\circ}$ (in garden earth, blackish gray). Taking the mean of summer temperature, this difference is, equal to a removal from the latitude of Massachusetts to that of South Carolina. The benefit of this increase in temperature is felt in the spring, by bringing the land into good condition to work two or three weeks earlier; and also in the fall, by keeping off the frost two or three weeks later. Crops may be planted earlier, will have, on account of the higher temperature, a more vigorous growth during the summer, and will have ample time to mature in the fall before they can be injured by frost.

Drains are peculiarly suited to our elimate.

The objection is often made that, though draining has been proved to be indispensable in Great Britain, yet here, on account of our drier climate, it is less needed. This is a false view of the subject. In England the fall, in a single day, of one inch vertical depth of rain is considered remarkable; while here the fall of three or four inches is not uncommon, and a fall of nearly seven inches has been measured. We need, then, provision for carrying away four times as much surplus water as is provided for in England. Beside this, the humidity of the English climate is such that the evaporation is only about half what it is here. We have seen how heat is lost by evapo- 
ration; so that on this account there is double the necessity for draining here.

Our atmosphere absorbs moisture so rapidly that the surface of retentive land is soon baked, and water cannot rise from below by capillary attraction, so that crops suffer from drought, an effect which we seek to arrest by mulching. Drains will keep this soil pulverized, so that water will rise freely by capillary attraction, in sufficient quantity for the use of the crops.

It would be impossible, in our limited space, to enumerate the many important details of construction that are necessary to insure an active and permanent drainage.

\section{Duties of the agricultural engineer.}

Any kind of work can be executed with greater efficiency and economy by a person who has made a careful study of the principles involved, and who has a thorough knowledge of the details of practical construction; and especially in draining, the work of a novice is often as expensive as it is clumsy. The agricultural engineer should be familiar with all that appertains to thorough draining; and it is his duty after being called upon by the proprietor, to examine the ground, (digging trial holes or a trial drain if necessary) in order to ascertain the character of the soil as to compactness, dip of strata, etc., and also to find whether the source of wetness is from beneath by springs, or from retention of surface water. If it is proposed to drain a large area, a careful topograph- 
ical survey and plan should be made to aid in establishing the system of drainage. This plan is also useful both for farming purposes and for landscapegardening. Having decided upon the outfall for the drain system, and the position of main, sub-main, and minor drains, as to their direction, distance apart, depth and grades, the whole should be staked out on the ground. The work may be let out by contract to be done under direction of the engineer; or men may be employed by the day under a competent overseer who attends to all details of the work, giving grades, etc., and who is employer and pay-master of the men. Much of the work on grounds of small area may be done by farm hands, under general direction of the engineer. Materials for the work can usually be procured by the engineer at a lower rate than by other parties. After the work is completed, a careful plan of the whole should be made, so that after the plough shall have obliterated all traces of the drains from the surface, any point in the system may still be easily found by means of the plan. 
SEE NEXT PAGE 
C. FOLLEN \& G. S. CURTIS,

\section{A RCHITECTS \\ AND}

\section{LANDSCAPE GARDENERS,}

110 TREM O T T T R E T,

B O S T O N. 


\section{U N D E R-D R A I N I N G.}

\section{SHEDD \& EDSON,}

\section{A G R I C U L T U R A L E N I N E E R S.}

HarE every facility for carrying on this department of Engineering, and they will render any assistance or advice that may be required of them by persons who are about executing a system of drainage either on a large or a small scale.

Complete and accurate topographical plans made to show the area of land and all its slopes or differences of level, upon which a system of drainage may be so well shown in erery particular, as to make them very valuable.

Draining Tile of all sizes furnished at the manufacturer's prices.

Office in the Iron Building -

NO. 42 COURT STREET, BOSTON.
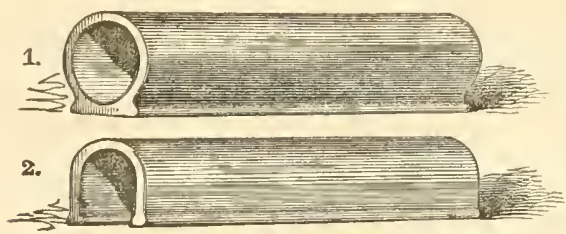

PRICES OF TILE AT THE MANUFACTORY:

SOLE TILE, (In form as No. 1.)

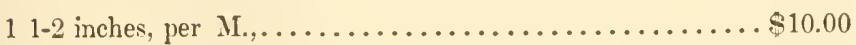

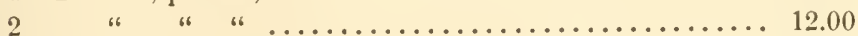

3 " " 3 "

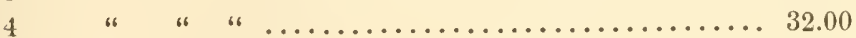

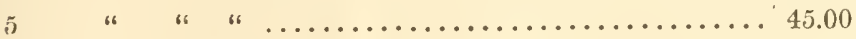

HORSE SHOE, (In form as No. 2.)

$21-2$ inches, per $11 ., \ldots \ldots \ldots \ldots \ldots \ldots \ldots \ldots \ldots \ldots \ldots \ldots 12.00$

$31-2$ " " " " 3 ".

$51-2$ " " " 
LIERARY OF CONGRESS

||||||||||||||||||||||||||||||||||||| 


\section{LIBRARY OF CONGRESS \\ 00214864307}

Metal Edge, Inc. 2007 P.A.T. 